\title{
Evaluation of television in the teaching of rheumatology
}

\author{
IAN HASLOCK,* V. WRIGHT, $\dagger$ J. H. IVES, $\ddagger$ AND D. J. G. HOLROYDE \\ From the Rheumatism Research Unit and the Television Service, University of Leeds
}

Increasing student numbers have encouraged universities to take greater interest in aids to conventional teaching methods. Television is establishing itself in this field, particularly when applied to clinical medicine, an aspect recently reviewed by Day (1972). In rheumatology this medium is little used at present. In his recent survey of teaching aids used in medical schools in Europe, Wood (1971) found that television was employed by only 4 per cent. Before the introduction of such techniques, however, it is necessary to evaluate their effectiveness as a teaching method, and this paper describes an evaluation of television, compared with the conventional lecture, in the teaching of rheumatology.

\section{Material and Methods}

The students investigated were in their first clinical term at the University of Leeds. This group was selected because their clinical experience was negligible and not subject to the variations in experience found among senior students. During the introductory course a single lecture is devoted to rheumatic diseases, particularly to the interpretation of signs elicited by clinical examination. The students attending the lecture were divided at random, half attending a conventional lecture, the rest a television presentation covering the same subject matter.

The conventional lecture followed the Unit's usual style of presentation which involves extensive use of slides, both clinical photographs and summary tables. The television presentation, as might be expected, enabled the material to be compressed into a period of approximately $20 \mathrm{~min}$. Within this time the presenter was able to show not only diagrams, $x$ rays, histograms, photographs, and other graphic material (including some animations of arm movement), but also five carefully planned excerpts of interviews with two patients. The cameras were able with speed and clarity to direct the students' attention to relevant symptoms and also, by means of an overhead camera, to show the close-up details of joint swellings and hand flexibility. Dialogue between doctor and patient was included.

The points made in the presentation concerning the main elements in diagnostic and examination procedure

Accepted for publication October 9, 1972

* William Hewitt Research Fellow

† Professor of R heumatology

$\ddagger$ Formerly Research Officer

$\S$ Director of Television were reinforced by captions, thus providing a visual dimension to the verbal exposition.

At the end of the teaching, a brief examination paper of the short answer type was given to the students who had been given no prior warning that the lecture would be in any way unusual and no intimation of the examination which followed it.

The questions put to the students were:

(1) What are the main symptoms relating directly to the patient's joints that must be elicited?

(2) In what ways might a rheumatic disease affect the patient's general health?

(3) Why is a thorough review of the systems symptomatically important in rheumatic diseases?

(4) Name a rheumatic disease where a family history may be helpful.

(5) What help is a social history in rheumatic disease?

(6) What points may emerge from the classical order of examination (inspection, palpation, percussion, auscultation) as far as joints are concerned ?

Those students attending the television presentation were also asked to complete an attitude survey in order to assess the impact of this method on them.

One month later, during the time allotted for a lecture on a different subject, the students were given the same question paper. Again no prior notice of the test was given. During this month the students had received their initial introduction in clinical methods on the wards, and should have been instructed in the examination of the locomotor system as part of this teaching.

The question papers were marked by the two clinicians in conference at a single sitting. The papers were thoroughly shuffled and the information concerning the students' names and the type of presentation attended was concealed from the markers to avoid bias.

\section{Results}

The results of the immediate test are shown in Table I (opposite). In four of the questions the television group scored higher marks, in one question the marks were equal, and in one question the lecture group scored a higher mark. The overall score for the television group was 60 per cent., that for the lecture group being lower at 52 per cent. $(t=2.3 ; \mathrm{P}<0.05)$.

For the delayed test three groups were available: those who had attended the television presentation, those who had attended the lecture, and those who 
Table I Comparison of marks (mean and standard deviation) obtained at immediate recall test

\begin{tabular}{|c|c|c|c|c|c|}
\hline \multirow{3}{*}{$\begin{array}{l}\text { Question } \\
\text { no. }\end{array}$} & \multicolumn{4}{|l|}{ Group } & \multirow{3}{*}{$\begin{array}{l}\text { Possible } \\
\text { marks }\end{array}$} \\
\hline & \multicolumn{2}{|c|}{ Television (25) } & \multicolumn{2}{|c|}{ Lecture (23) } & \\
\hline & Mean & S.D. & Mean & S.D. & \\
\hline $\begin{array}{l}1 \\
2 \\
3 \\
4 \\
5 \\
6\end{array}$ & $\begin{array}{l}49 \\
14 \\
22 \\
10 \\
24 \\
68\end{array}$ & $\begin{array}{r}6 \\
16 \\
9 \\
0 \\
13 \\
15\end{array}$ & $\begin{array}{r}42 \\
18 \\
22 \\
6 \\
16 \\
57\end{array}$ & $\begin{array}{r}9 \\
17 \\
9 \\
5 \\
12 \\
18\end{array}$ & $\begin{array}{r}70 \\
40 \\
40 \\
10 \\
40 \\
110\end{array}$ \\
\hline Total & 186 & 32 & 161 & 41 & 310 \\
\hline
\end{tabular}

had attended neither, being absent at the time of the initial presentations. The test results are shown in Table II and the performance of the groups is compared statistically in Table III. The only significant difference in performance was between the television group and the 'neither' group.

Table II Comparison of marks (mean and standard deviation) obtained at delayed recall test

\begin{tabular}{|c|c|c|c|c|c|c|}
\hline \multirow{3}{*}{$\begin{array}{l}\text { Question } \\
\text { no. }\end{array}$} & \multicolumn{6}{|l|}{ Group } \\
\hline & \multicolumn{2}{|c|}{$\begin{array}{l}\text { Television } \\
\text { (20) }\end{array}$} & \multicolumn{2}{|c|}{$\begin{array}{l}\text { Lecture } \\
\text { (15) }\end{array}$} & \multicolumn{2}{|c|}{$\begin{array}{l}\text { 'Neither' } \\
\text { (11) }\end{array}$} \\
\hline & Mean & S.D. & Mean & S.D. & Mean & S.D. \\
\hline $\begin{array}{l}1 \\
2 \\
3 \\
4 \\
5 \\
6\end{array}$ & $\begin{array}{r}36 \\
1 \\
14 \\
6 \\
18 \\
56\end{array}$ & $\begin{array}{r}11 \\
4 \\
8 \\
5 \\
12 \\
16\end{array}$ & $\begin{array}{r}36 \\
5 \\
16 \\
4 \\
16 \\
44\end{array}$ & $\begin{array}{r}6 \\
7 \\
11 \\
5 \\
15 \\
18\end{array}$ & $\begin{array}{r}27 \\
5 \\
11 \\
1 \\
9 \\
45\end{array}$ & $\begin{array}{r}10 \\
8 \\
5 \\
3 \\
7 \\
14\end{array}$ \\
\hline Total & 13 & 29 & 121 & 40 & 98 & 28 \\
\hline
\end{tabular}

Table III Comparison of mean marks obtained by three groups

\begin{tabular}{|c|c|c|c|}
\hline Group & Television & Lecture & 'Neither' \\
\hline Lecture & $\begin{array}{l}t<1 \\
\text { N.S. }\end{array}$ & - & $\begin{array}{l}t=1 \cdot 6 \\
\text { N.S. }\end{array}$ \\
\hline 'Neither' & $\begin{array}{l}t=2.9 \\
P<0.01\end{array}$ & $\begin{array}{l}t=1 \cdot 6 \\
\text { N.S. }\end{array}$ & - \\
\hline
\end{tabular}

N.S. $=$ not significant

The results showed no significant correlation with the marks obtained by the students in their 2nd M.B. examination.

In the attitude questionnaire the overall result showed that the students considered the presentation of the television programme was good and well produced. They found the subject matter interesting and would not have preferred a lecture presentation. Their overall reaction towards more extensive use of television in teaching was favourable.

\section{Discussion}

The first benefit from the experiment accrued to the two clinicians who usually presented the conventional lecture. The content of this had originally been decided several years ago and the presentation modified a little each succeeding year. The overall presentation time had been approximately $40 \mathrm{~min}$. When the design of the television programme was considered, an analysis was made of what knowledge should be imparted by a lecture of this type. This resulted in a drastic pruning of the material, so that the eventual lecture and television presentation each took $20 \mathrm{~min}$.

The original object of the clinicians had been simply to record the lecture, with its slides, so that the two presentations would be identical. On further consideration, however, it was felt that this was an inappropriate way of using the medium, which would lose both the personal presence and the use of colour (the Leeds University Television Service being at present restricted to black-and-white productions) without being given the opportunity to demonstrate its potential advantages. The final programme therefore took the form of a central narrative, presented by the lecturer, interspersed with clinical interviews, still animated diagrams, and summary charts.

One advantage claimed for televising lectures is that time is subsequently saved by lecturers. This presentation, however, took the equivalent of 10 years' lecturing time to prepare.

To the students it appeared that television presentation was advantageous compared with a lecture at the time of the immediate recall test. This was in contrast to the reaction of students in other disciplines in the university. It would appear that the visual content of clinical medicine and the interview situations lend themselves well to this type of production. The reduction of the time of the programme to $20 \mathrm{~min}$. by careful scrutiny of the material was fortuitous, but was also fortunate in that there is evidence to suggest that the effectiveness of television teaching diminishes beyond this length.

The marks of the television group were superior to the 'neither' group at delayed recall, although the difference from the conventional lecture had disappeared. An alternative way of looking at these results is to assess the amount which each group had forgotten between the tests. This is summarized in Table IV (overleaf), the numbers have been amended so that only those students appearing for both tests are included. The loss of information by the television group is almost twice that of the lecture group. Both groups had received a similar amount of clinical teaching during the interim period. 
Table IV Comparison of marks (expressed in percentages) at immediate and delayed recall tests, showing loss of information

\begin{tabular}{|c|c|c|}
\hline \multirow[t]{2}{*}{ Marks } & \multicolumn{2}{|l|}{ Group } \\
\hline & Television (20) & Lecture (15) \\
\hline $\begin{array}{l}\text { Immediate } \\
\text { Delayed }\end{array}$ & $\begin{array}{l}60 \\
42\end{array}$ & $\begin{array}{l}49 \\
39\end{array}$ \\
\hline Loss & 18 & 10 \\
\hline
\end{tabular}

\section{Conclusions}

It appears that television is an adjunct to teaching which proved popular with medical students but was not significantly time-saving to their teachers. The initial impact of the television presentation was such that those students who had seen it received higher marks in an immediate recall test than those attending a conventional lecture of similar content, but this superiority was lost after a 4-week interval during which the students had received similar amounts of clinical teaching. The main benefit of the exercise as organized on this occasion was to the teaching staff. The presentation, however, was pre-recorded and is available in the library for review, as one of a number of such videotapes being used on an experimental basis. It seems likely that this use of television will prove more useful to the students and more economical to their teachers' time than simple replacement of a lecture.
Our present practice is to show the Arthritis and Rheumatism Council film "A Touch of Rheumatism" to give a general view of the subject (usually greeted with much interest and great hilarity); this is followed by the television presentation, and the session is concluded with an opportunity for discussion.

\section{Summary}

The introductory lecture in Rheumatology for the first clinical term medical students at the University of Leeds was replaced for a random half of the class by a television presentation. This was followed by a test concerning the subject matter in which the performance of the television group significantly exceeded that of the lecture group $(P<0.05)$. One month later the same test was applied, and a third group of students (those who had not attended the first presentation) was also available on this occasion. The only significant difference among the marks obtained was between the television and 'neither' groups $(P<0.01)$. The television presentation utilized a wide range of visual techniques not available to the lecturer, and proved popular with the students. It did not result in saving of lecturers' time, however, and its preparation probably gave more benefit to the teachers than the students.

We are grateful to Miss N. Nesteroff for her production of the programme, to Mr. Arthur Moreton for technical assistance, and to the patients who participated.

\section{References}

DAY, J. (1972) Med. Teacher, 1, no. 4, p. 11 (Television in medical teaching)

Wood, P. N. H. (1971) 'Proceedings VII European Congress of Rheumatology', Abstr. 1.8 (Undergraduate teaching and rheumatology) 